\title{
Masculinidades e práticas de saúde: retratos da experiência de pesquisa em Florianópolis/SC
}

I ${ }^{1}$ Maria Juracy Filgueiras Toneli, ${ }^{2}$ Marina Gomes Coelho de Souza,

${ }^{3}$ Rita de C. Flores Müller I

Resumo: Este artigo tem o objetivo de apresentar parte dos resultados da pesquisa multicêntrica "Masculinidades e Práticas de Saúde”, em que foram investigados, junto à população masculina de Florianópolis (SC), os significados sobre saúde/doença e práticas de cuidados com a saúde por ela desenvolvidas. Para tal, foram realizados sete grupos focais com homens usuários dos serviços de saúde, entrevistas com os profissionais que compõem a equipe técnica de saúde sexual e reprodutiva do Hospital Universitário (HU) da Universidade Federal de Santa Catarina (UFSC), bem como 260 entrevistas com homens. Investigou também, junto à equipe de profissionais do serviço (médicos, enfermeiros, psicólogos, assistentes sociais, gestores em saúde), as discursividades de gênero em relação aos cuidados com a saúde e promoção do acesso de homens aos serviços. A proposta filosóficometodológica de Judith Butler sobre gênero inteligível, performatividade e suas implicações na constituição de sujeitos em saúde foi o vetor de análise do material empírico da pesquisa, sem perder de vista o projeto biopolítico em que estes enunciados são possíveis de serem formulados, principalmente no que se refere ao SUS e a seus princípios de universalidade, integralidade e equidade. A categoria gênero é elemento de grande importância no padrão dos riscos de saúde nos homens e na forma como estes percebem, usam e cuidam de seus corpos, tanto como possibilidade de transformação de valores como na reiteração dos vigentes.

> Palavras-chave: homens, saúde, masculinidades.

\author{
1 Departamento de Psicologia/ \\ UFSC. Professora Associada \\ II. Doutora em Psicologia. \\ Endereço eletrônico: juracy@ \\ cfh.ufsc.br. \\ ${ }^{2}$ Graduanda em Psicologia pela \\ UFSC. Endereço eletrônico: \\ psicomarina@gmail.com \\ ${ }^{3}$ Doutoranda em Teoria \\ Psicanalítica pela UFRJ, com \\ bolsa da CAPES. Endereço \\ eletrônico: ritafloresmuller@ \\ gmail.com.
}


Apesar de há muito se saber da relação intrínseca entre gênero e saúde, é relativamente recente o interesse da saúde pública na temática da saúde masculina (GREIG; KIMMEL; LANG, 2000). No Brasil, por exemplo, o primeiro artigo relacionando homens e saúde foi publicado em 1998. No início da década de 90, algumas conferências internacionais relativas aos direitos das mulheres já salientavam, de forma mais explícita, a necessidade de incorporar os homens como forma de alcançar maior equidade de gênero. Foram elas: a Conferência sobre População e Desenvolvimento, realizada no Cairo em 1994, e a IV Conferência Mundial sobre a Mulher, em Beijing, no ano de 1995. No que se refere às formas de violência, principalmente a violência doméstica; à saúde sexual e reprodutiva; às mudanças do perfil epidemiológico do HIV/Aids, uma urgência em se trabalhar com os homens e o masculino se fez premente (HEILBORN; CARRARA, 1998). Nos três eixos de ação, a presença dos homens nos debates tornou-se uma premissa fundamental para que as agendas feministas tivessem êxito no alcance político das lutas pelos direitos das mulheres, nos mais diversos âmbitos da constituição desses sujeitos. A crescente visibilidade da violência doméstica e o aumento da contaminação sexual de mulheres por seus parceiros fixos provocaram um deslocamento das esferas do privado para o público, o que possibilitou que estas questôes fossem consideradas, no âmbito da Saúde Coletiva, passíveis de controle e atenção do estado e da sociedade civil.

No Brasil, como na América Latina, esses estudos surgem inspirados pelas teorias de gênero. Configura-se neste contexto a emergência do Programa de Treinamento em Pesquisa sobre Direitos Reprodutivos na América Latina e Caribe (PRODIR), sediado na Fundação Carlos Chagas, entre 1990 e 2003. A realização do terceiro PRODIR foi dedicada ao tema das masculinidades, em que pela primeira vez se observou um maior número de homens pesquisadores inscritos no concurso. Além disso, a tendência anterior de se estudar sexualidade e reprodução tendo como foco as mulheres foi problematizada. E, por fim, com a realização destas pesquisas, foi questionada a associação direta dos homens à violência, ao assédio, ao estupro, à agressividade, para ser refletido em termos de plural e não de singulares, hegemônicos, universais.

Em 2006, o ministro da Saúde brasileiro, José Gomes Temporão, em seu discurso de posse, estipulou como uma das metas do plano de ação de seu governo, 
para o Sistema Único de Saúde (SUS), a atenção à saúde do homem. ${ }^{1}$ Esta meta teve seu pontapé inicial em agosto deste ano, com o lançamento da Política Nacional de Atenção Integral à Saúde do Homem (PNAISH). Isto reflete a amplitude da temática de homens e serviços, que vem sendo alvo de atenção de pesquisadores/as das mais diversas áreas do Brasil e América Latina (GIFFIN, 2005; ARILHA, 1998; TONELI, 2000; NASCIMENTO, 2005; SCHRAIBER; GOMES; COUTO, 2005). O interesse na América Latina e Caribe por experiências de trabalho com homens, em sexualidade e saúde reprodutiva, vem crescendo nos últimos anos, sobretudo a partir de demandas que têm origem em ações desenvolvidas com mulheres, em diferentes campos (LYRA; MEDRADO, 2005). Em revisão de literatura de pesquisas sobre o tema, Gomes e Ferreira (2006) destacam que a produção encontrada concentra-se na temática da saúde sexual e reprodutiva. Contudo, há um crescente interesse neste assunto nos últimos anos, sobretudo a partir de demandas que têm origem em ações desenvolvidas com mulheres (LYRA; MEDRADO, 2005). Segundo Arilha (2001), o reconhecimento da importância de enfocar os homens na área da saúde reprodutiva deveu-se, em grande parte, à urgência imposta pela pandemia de HIV/Aids, à crescente visibilidade da violência contra mulheres baseadas nas desigualdades de gênero e seu desequilíbrio nas decisões e cuidados no campo da saúde sexual e reprodutiva. Com o aumento da transmissão por via heterossexual, as crescentes taxas de infecção entre mulheres e a consequente mudança do perfil epidemiológico da Aids, os estudos passam a buscar a incorporação da perspectiva de gênero para entender o aspecto relacional da conjugalidade-afetividade e sua conexão com HIV-Aids.

A ênfase no caráter relacional do gênero não é sem consequências, nem tampouco simples de ser apreendida como um dispositivo de análise das questóes relativas à temática de homens e saúde. Afirmar tais noções de gênero acerca de sua relação com a percepção das diferenças sexuais e de seu caráter relacional pode indicar, além de mais do mesmo, um caminho que nos conduz a uma leitura superficial das questôes (SCOTT, 1995, 2005). Ou seja, pode remeter à naturalização da própria relação, resvalando na essencialização mesma que pretende negar. Importante considerar, ainda, que o caráter relacional do gênero remete à regulação das relaçôes e práticas sociais (BUTLER, 2003). Bird e Rieker (1999) destacam que, com a entrada da perspectiva de gênero, a maioria das doenças passa a ser considerada como uma combinação de causas biológicas e socioculturais que podem promover a ampliação ou supressão de riscos de 
doença na população masculina, uma vez que há uma base biológica que pode ser acentuada ou diminuída pelo contexto sociocultural. Sabo (2000) e Courtenay (2000) demonstram que, na construção de gênero, muitos homens assumem riscos que interferem em suas condiçōes de saúde. Essa construção também define a forma como os homens usam e percebem seus corpos. Nas perspectivas de seus modelos de masculinidade, os homens muitas vezes assumem comportamentos considerados pouco saudáveis, comportamentos esses que estão relacionados a um modelo de masculinidade idealizada (CONNELL, 1995).

O conceito de "masculinidade hegemônica", cunhado por Connell (1997), permite-nos refletir sobre a expressão de uma forma de masculinidade dominante, mais valorizada e idealizada em determinado contexto sócio-histórico, também denominado de modelo tradicional de masculinidade, considerado aqui não apenas em suas características normativas, mas como uma construção social polêmica, estereotipada, que se reflete nas práticas que engendra. Segundo Mosse (1996), a construção histórica do estereótipo de masculinidade fornece as bases para o modelo hegemônico e normativo do "homem de verdade" ocidental. Esse ideal a ser alcançado é parte integrante do funcionamento da sociedade e valoriza as seguintes características: ser viril e conquistador, ter sucesso e poder, ser forte e agressivo, ter honra para lutar por um ideal maior, ter coragem para assumir riscos, dar proteção aos mais fracos, ser leal com os companheiros, ter força de vontade e autocontrole emocional (MOSSE, 1996; KIMMEL, 1997; SABO, 2000; RIBEIRO; ALMEIDA, 2003).

Como elementos constituintes das representações sociais de masculinidade, essas características têm sido encontradas, em menor ou maior grau, em diferentes grupos culturais das sociedades ocidentais e vêm orientando práticas que mostram as consequências do modelo hegemônico em dois níveis: no tipo de sociedade que se constrói e na qualidade de vida das pessoas. Wade e BrittanPowell (2001) mostram que características próprias ao modelo hegemônico de masculinidade estão fortemente relacionadas a violências de gênero, racismo, xenofobia, intolerância religiosa, entre outras diversas formas de preconceito e discriminação, que produzem consequências graves no que concerne aos direitos humanos. Além disso, homens que aderem mais fortemente aos padrōes masculinos tradicionais se veem envolvidos com práticas homofóbicas, explícitas ou implícitas, desde muito precocemente (PLUMMER, 2001). 
Diversos autores apontam que a adesão ao modelo hegemônico está relacionada a um aumento de risco de doenças e dos índices de mortalidade masculina (COURTENAY, 2000; SABO, 2000; FRAGOSO; KASHUBECK, 2000; GUERRIERO; AYRES; HEARST, 2002). Em revisão da literatura sobre questôes concernentes à saúde do homem norte-americano, Courtenay (2000) assinala que a adoção desse modelo está associada às três principais causas de morte em homens entre 15 e 35 anos: os ferimentos não intencionais, o homicídio e o suicídio. Verificou ainda que os homens que aderem ao modelo tradicional têm menor probabilidade de adquirir hábitos de cuidado da saúde; apresentam maior risco de sofrer depressão e fadiga nervosa; têm maior reatividade cardiovascular em situações de estresse. Além disso, Sabo (2000, p. 6) mostra que jovens norte-americanos integrados ao modelo hegemônico são jovens em situação de risco, podendo prejudicar também as pessoas com quem convivem, "a ideologia masculina foi associada a expulsões escolares, consumo de álcool e uso de drogas ilícitas, detenções policiais, número de parceiras sexuais e enganar ou forçar outras pessoas para manter relações sexuais”. Apesar disso, homens com estas características raramente procuram ajuda psicológica e médica (ROBERTSON; FITZGERALD, 1992). Relacionar-se de forma íntima com os riscos, com a vulnerabilidade, com as diversas expressóes de violência, pode ser a condição para muitos homens permanecerem identificados aos avatares da masculinidade, por meio de uma repetição estilizada de atos (BUTLER, 2003, p. 200), uma exacerbação de um duelo constitutivo dos sujeitos.

Segundo Schraiber, Gomes e Couto (2005), na temática da morbimortalidade dos indivíduos de sexo masculino, quando se consideram o câncer de pulmão e o de próstata, ressaltam-se dois comportamentos culturalmente marcados pelas distinçôes de gênero: o hábito de fumar, fator de risco bem estabelecido para o câncer de pulmão, e o padrão de uso dos serviços de saúde, no caso do câncer de próstata, denotando a forma de relacionar-se com ações preventivas para o cuidado de si.

Em relação às questôes da prevenção e da promoção, pode-se perceber que os efeitos do movimento de incluir o homem no debate sobre saúde não se restringem à saúde masculina. Afetam, conferindo-lhes força e potencializando esforços, os programas de gênero destinados à saúde das mulheres e das crianças, pois permitem que homens se familiarizem com a participação nas questões que 
envolvem, por exemplo, a prevenção e promoção de saúde, incluindo a ampliação da noção de cuidado de si e dos outros; a saúde sexual e a saúde reprodutiva; as reflexões sobre as violências de gênero; a atribuição de responsabilidades aos homens em relação ao exercício da sexualidade, face aos efeitos limitadores de padrões culturais incorporados cotidianamente e expressos por tônicas sexistas e preconceituosas. Por consequência, ressaltam-se o caráter relacional das problemáticas de saúde, o próprio caráter social do adoecimento e a perspectiva de gênero como forma particular de compreensão da relação saúde-sociedade. Desta forma, conseguem-se ganhos também para a saúde feminina em temas que só avançam na medida em que se consegue a participação masculina em seu enfrentamento (KEIJZER, 2003, SCHRAIBER; GOMES; COUTO, 2005).

De acordo com Knauth e Machado (2005, p. 19), “esta perspectiva impóe uma abordagem centrada no caráter relacional e, portanto, não basta incluir os homens, mas a própria forma de trabalhar com as mulheres deve ser repensada”. Sem dúvida, a promoção das discussões acerca de homens e saúde no campo dos estudos de gênero vem contribuir para uma visada relacional da problemática em saúde e prevenção.

Buscar conhecer as explicações presentes em discursos masculinos sobre a procura dos homens por serviços de saúde, suas representações sobre esses serviços e relações de grupos que interagem nesse complexo sistema apresenta-se como um caminho promissor na discussão sobre as dificuldades, os obstáculos e as resistências associadas à saúde dos homens numa dimensão relacional de gênero. Reconhecer a necessidade de olhar para estas questóes é aceitar o desafio de trabalho frente à resistência do masculino no próprio campo dos estudos de gênero. Uma resistência que advém não apenas dos homens, relacionada à presença ou à ausência destes quando são chamados a participar na divisão das responsabilidades com as mulheres, mas, principalmente, uma dificuldade em lidar com esta presença que se objetivava (até então) justamente na ausência dos homens nos serviços de saúde.

A partir destas considerações, definiu-se como objetivo deste estudo investigar junto à população masculina de Florianópolis os significados sobre a saúde/ doença dos homens, e quais são as práticas por eles desenvolvidas relacionadas à promoção de saúde ou prevenção de doenças. Buscou-se, ainda, identificar alguns dos sentidos sobre saúde reprodutiva e os cuidados pessoais relacionados à sua prevenção, bem como investigar junto à equipe técnica de programas e 
serviços voltados à saúde sexual e reprodutiva, as representações de gênero e o que gravita em torno da relação de homens com a saúde. Neste caso, utilizando a proposta teórico-metodológica de Judith Butler (2005), ao falar da eficácia dos imperativos acerca do masculino e a saúde/doença, o discurso se torna produtivo dos cerceamentos que demarcam espaços autorizados e/ou reconhecidos na vivência dos gêneros, mas principalmente, "faz nascer o ser" homem que não encontra espaço possível no campo da saúde. O que este artigo propóe é que lidemos com estes cerceamentos com vistas a ampliar nossas fronteiras na busca por uma maior equidade e acesso à saúde para homens e mulheres.

\section{Abordagem metodológica}

A pesquisa foi realizada no primeiro semestre de 2008 junto a 260 homens usuários dos serviços de saúde de Florianópolis e 11 profissionais gerentes e/ou coordenadores de serviços e programas voltados à saúde sexual e reprodutiva. Os 260 homens respondentes foram divididos nos seguintes grupos: 130 jovens de 18 a 25 anos, sendo 65 matriculados em escolas públicas e 65 em escolas particulares e 130 adultos de 45 a 55 anos, sendo 65 com curso superior completo e 65 que tinham, no máximo, ensino fundamental. Os grupos focais foram em número de sete e seguiram o mesmo recorte utilizado na aplicação dos questionários.

$\mathrm{Na}$ seleção dos profissionais da área da saúde, foram priorizados aqueles que trabalhavam na coordenação ou gerência de programas/serviços de saúde sexual e reprodutiva do Hospital Universitário (HU) de Florianópolis. O HU é uma unidade hospitalar de referência pública, que atende à clientela do SUS no Estado de Santa Catarina e foi reconhecido como um espaço privilegiado para a realização da pesquisa multicêntrica, tendo em vista o amplo alcance de atendimento desta instituição, seu reconhecimento e confiabilidade perante a comunidade, bem como a amplitude dos programas que desenvolve e que envolvem aspectos relacionados aos direitos sexuais e direitos reprodutivos. ${ }^{2}$ Ao todo, foram 11 entrevistas com coordenadoras e coordenadores dos programas de saúde sexual e reprodutiva do hospital universitário.

Foram feitas entrevistas semiestruturadas, ${ }^{3}$ realizadas em horários e locais escolhidos pelos entrevistados. Nesse tipo de coleta, procurou-se estabelecer uma conversa dirigida com os pesquisados em torno de temas que integravam o objeto da pesquisa. $\mathrm{O}$ roteiro preestabelecido apresentou os seguintes focos 
investigativos: cuidados com a saúde, importância da presença dos homens nos serviços públicos, implementação de programas voltados aos homens, significados de "ser homem", dificuldades para a participação destes nos serviços de saúde, a relação entre os/as profissionais e os homens.

No tocante aos aspectos éticos da pesquisa, foram respeitados os princípios da Resolução no 196/96 do Ministério da Saúde. O projeto foi aprovado pelo Comitê de Ética em Pesquisa da Universidade Federal de Santa Catarina (UFSC), pelas instituiçôes participantes ${ }^{4}$ e pelos sujeitos, através da assinatura do Termo de Consentimento Livre e Esclarecido.

\section{Sobre as entrevistas com profissionais de saúde do hospital universitário}

As duas questôes iniciais do roteiro foram: quem cuida mais da saúde: o homem ou a mulher? Como os homens cuidam da saúde? Ou seja, entre o "quem cuida mais" e "como cuida", há indicativos de uma analítica do gênero que "pressupõem e definem por antecipação as possibilidades das configurações imagináveis e realizáveis do gênero na cultura" (BUTLER, 2003, p. 28). Com relação à questão do cuidado com a saúde, foi predominante entre os profissionais o fato de que as mulheres cuidam mais da saúde e o fazem preventivamente, e os homens não cuidam e o fazem curativamente. Há, no entanto, uma primazia do cuidado biomédico em detrimento do cuidado associado às práticas de bem-estar social, como a rotina esportiva e cuidados com a alimentação relatada pelos homens. A diferença sexual como acionador das justificativas entre homens e mulheres submete os corpos a diferentes lógicas e tecnologias de cuidado (FOUCAULT, 2004). Talvez haja, no campo da saúde, não apenas um modelo de cuidado com a saúde (promoção/ prevenção), fundado nos princípios de uma ciência biomédica, mas também a prerrogativa de que homens e mulheres se adequem a um modelo universal, tanto no que se refere às práticas de cuidado com a saúde, quanto aos modos de ser "cuidador", em relação ao cuidado de si e dos outros. 5 Alguns profissionais questionam esta concepção de saúde e de cuidado intensamente marcado pela concepção biomédica (KNAUTH; MACHADO, 2005), segundo Maura, ${ }^{6}$ enfermeira da Unidade de Neonatologia:

Atualmente eu acho relativo. Acredito que hoje o homem cuida mais da saúde dele próprio. Eu colocaria esse cuidado com a saúde entre aspas, porque o cuidado com a saúde 
aí está mais ligado ao médico, procurar mais o médico que a mulher, mas, em contrapartida, eles não têm o respeito muito grande com eles próprios (enfermeira, 55 anos).

Os relatos apontam a questão da pluralidade, considerando que os profissionais estão falando de diferentes maneiras de ser homem, numa tentativa de implodir com o dito "homem é tudo igual". Se, por um lado, seja o "homem com b" o herdeiro vitalício das características totalizantes e hegemônicas de um sujeito universal, por outro ele difere daquele com o qual os entrevistados estão buscando dialogar. Segundo Nascimento (2005, p. 26): "não se pode desconsiderar a existência dos diferentes estilos de masculinidade, pois na vida cotidiana devemos levar em conta a posição concreta e particular dos sujeitos em cada grupo de referência".

A luta de alguns segmentos do HU pela implementação do ambulatório de saúde do adolescente reflete o compromisso estabelecido por profissionais de saúde em relação ao público masculino atendido na instituição. $\mathrm{O}$ trecho da entrevista é de um dos médicos engajados na implantação do Ambulatório de Saúde do Adolescente que, segundo ele, é fundamental para acabar com o hiato entre a pediatria e a clínica geral:

Como eu trabalho na área de adolescência, existe o hábito de se jogarem as questôes preventivas em relação até a própria gravidez na adolescência, as práticas de anticoncepção, nas costas da mulher. Então quando os meninos vêm, a gente consegue abordar questôes relacionadas ao respeito entre os indivíduos, salientar responsabilidades do menino, do jovem, nas práticas destes métodos anticoncepcionais. Isto gratifica no sentido de você estar tentando mudar o perfil do homem, daqui a cinco, 10, 15 anos (médico, 50 anos).

"Criar essa cultura no adolescente", "mudar o perfil do homem", "questóes relacionadas ao respeito entre os indivíduos, salientar responsabilidades", estas são tônicas importantes que refletem alguns entraves sócio-culturais que afastam a população masculina dos serviços de saúde, ao mesmo tempo em que refletem a preocupação de alguns profissionais em atender a esta população que não está contemplada pelos programas e serviços que existem.

$\mathrm{Na}$ fala da enfermeira do ambulatório DST/Aids, a questão da procura pelos serviços está também marcada pelo retrato das demandas estabelecidas de acordo com as faixas etárias. No entanto, parece que a distância mantida pelos homens em relação à instituição de saúde é uma constatação, segundo ela:

No nosso ambulatório tem uma demanda muito engraçada, ou é o adolescente, o jovem que vem em função de alguma atividade de risco que teve, ou por ter adquirido 
alguma DST pela iniciação; ou a nossa faixa etária é em sua grande maioria homens de acima de 40 anos, porque aí já começam a aparecer alguns sintomas, e depois é o homem a partir dos 70 anos, esse sim, depois que o exame foi feito aí ele começa a fazer seu controle periódico direitinho. (enfermeira, 50 anos).

O caráter performativo da diferença sexual incide sobre a divisão binária dos cuidados com a saúde, em que os homens estariam tão afastados do cuidado preventivo quanto o estão dos serviços. Estes elementos de análise estão circunscritos no âmbito das tecnologias do poder (FOUCAULT, 2003), em que a sexualidade, o papel central da família na vigilância da saúde e a medicalização dos corpos são topos de análise e constituição dos saberes a partir do século XVIII. Daí a força do feminino que vê na governabilidade da vida seu lugar de existência, na figura da mulher-mãe. Esta força aparece discursivamente atualizada tanto nas entrevistas com os profissionais de saúde quanto com os usuários dos serviços públicos, esta mulher detentora do saber sobre a saúde dela, da criança e do parceiro, constituindo-se no sujeito universal do cuidado do SUS (MÜLLER, 2008). Para os profissionais, o cuidado aprendido alia-se à responsabilidade do cuidado para e com: com os filhos, com a reprodução; cuidados para não engravidar, para tomar o anticoncepcional, etc. Neste sentido, as mulheres constituem-se em inteligibilidades do SUS, importantes alvos de alcance e de ação na governabilidade de suas próprias vidas e daquelas pelas quais assume a responsabilidade.

Quando questionados sobre o porquê de os homens procurarem menos pelos serviços de saúde, a díade natureza/cultura reaparece como o binômio por excelência para falar de homens e saúde. É ela quem movimenta as justificativas que afastam os homens dos serviços, ao mesmo tempo em que reitera e autoriza a presença das mulheres neste campo de cuidados como sujeito legítimo de direitos. O corpo tem sua centralidade na medida em que se movimenta tanto pelas ordens do cultural e do natural, ambas entendidas como atos performativos contingentes na produção/repetição/manutenção do gênero binário, parte do processo de naturalização que o próprio gênero requer para que (se) sustente (sobre) os efeitos substancializantes constituintes do sujeito. Nas produçōes discursivas dos entrevistados, este binômio se materializa nos obstáculos dos homens em direção à saúde, conforme a fala a seguir, em resposta à pergunta sobre o porquê da menor procura destes pelos serviços de saúde:

São as restrições naturais. Pela própria característica da personalidade feminina, que possibilita a ela buscar os filhos, temos o contraponto da personalidade masculina, de 
ter esta dificuldade. O contraponto de ao homem não ter dado o direito de ficar doen-

te, de pedir ajuda, de pedir colo, de chorar. Então o homem tem uma resistência muito maior de aceitar a necessidade de precisar de ajuda. Este é obstáculo importante que a gente vê tanto nas patologias, na disfunção sexual, em tudo. (médico, 45 anos).

Outra resistência é a questão econômica. É muito mais difícil o homem aceitar que tem que deixar de trabalhar para comparecer a uma consulta de planejamento familiar do que conseguir esta liberação para a mulher. Este é um argumento muito colocado, e é uma coisa cultural mesmo, então existe uma dificuldade em trazer o homem para a reunião de planejamento familiar, existe uma dificuldade para o grupo de gestantes, de acompanhar o pré-natal, de acompanhar a ultrassom. (idem).

As entrevistas com os gestores de saúde indicam a complexa teia de significados que circulam na instituição, e que envolvem não só os homens, mas as mulheres, as ordens sociais como um todo, principalmente em práticas discursivas que reiteram o afastamento dos homens no diâmetro da saúde. Alguns descompassos, alguns desencontros que, não gratuitamente, fixam estereótipos de gênero muito calcados em lógicas binárias. Ao "reintegrar o fruto de seu próprio ventre", a mulher é constituída simbólica e materialmente uma mãe "desde sempre" assim concebida, uma unidade que teve seu referente tradicional e inteligível fundido ao seu significado, e que diz de uma ontologia maternal (BUTLER, 1998, p. 25). Por outro lado, a partir da fala dos entrevistados, percebe-se a força do significante trabalhador tanto para afastar quanto para aproximar os homens dos serviços de saúde, seja pela invisibilidade, seja pela atualização do homem-provedor que em prol da família não tem tempo de cuidar da saúde.

Concebida em seu sentido masculino e universal, a categoria trabalhador concede às mulheres o lugar de invisibilidade. A afirmação de um dos profissionais entrevistados, ao refletir sobre a pergunta "por que as mulheres procuram mais os serviços de saúde que os homens?", é emblemática neste sentido, pois demarca o espaço do furo discursivo que o termo trabalhador mascara:

Esse papo que mulher não trabalha é papo furado, porque o trabalho de casa dá muito trabalho e na sociedade rural a mulher sempre trabalhou, a mulher tinha uma tarefa, o homem tinha outra tarefa e os dois trabalhavam (médico, 50 anos).

A segunda questão, paradoxalmente, diz desta invisibilidade também referida aos homens, e a partir dela, reflete em que sentido as questôes estruturais do trabalho são entraves para a aproximação dos homens nos serviços de saúde, bem como é o resquício de patriarcado na atualidade. Estas questóes permanecem contempladas nas entrevistas com os usuários dos serviços de saúde, quando se 
relacionam às questôes de infraestrutura dos serviços públicos no atendimento aos homens: horários para atendimento, longas filas, atestados que comprove a permanência do homem no hospital, a dispensa para consultas médicas.

\section{Sobre as entrevistas com os usuários dos serviços de saúde} A delimitação discursiva das diferenças é a tônica na cartografia da saúde/doença e sua relação com cuidado para homens e mulheres. Dito isto, as diferenças existem e sustentam/são sustentadas pelo aparato do gênero inteligível em sua matriz heteronormativa. Neste sentido, à divisão sexual do cuidado imbricam-se os significados simbólico-culturais sobre o masculino e o feminino:

A mulher tem uma preocupação maior para cuidar de si e dos outros. O homem é mais relaxado, menos cuidadoso. (Adulto nível superior, 49 anos).

É cultural. Na cultura latina principalmente. $\mathrm{O}$ homem não demonstra fraqueza, desde menino. (Jovem de escola particular, 19 anos).

Também é uma questão da sociedade. A maneira como o menino é educado. Aquele que comanda, que é auto-suficiente. (Jovem de escola pública, 22 anos).

Por uma questão cultural, o homem sempre trabalhou e a mulher cuidou da casa e dos filhos. Hoje esta situação está se revertendo. A mulher está ativa no trabalho com mais ou menos $50 \%$ e o quadro acredito seja que ela vá ter o mesmo comportamento do homem logo. (Adulto nível superior, 51 anos).

$\mathrm{O}$ argumento de que a mulher está mais próxima do cuidado preventivo e o homem ao cuidado que atenda às necessidades imediatas, "curativas", é recorrente entre os entrevistados e se justifica pela legitimidade de um corpo que é gerador de vida. Por outro lado, ao afirmarem que apenas procuram o serviço no extremo de suportabilidade, estes sujeitos estão levando a termo a expressão do "até onde o corpo aguenta" (KEIJZER, 2006), bem como se aproximando da assertiva de um dos médicos entrevistados que afirmou: "os homens são assintomáticos". Foram recorrentes, por parte dos usuários dos serviços, afirmaçôes do tipo: "eu só procuro o médico quando estou morrendo".

$\mathrm{O}$ retorno às explicações de ordem biológica justifica a rotina de maior cuidado com a saúde à que a mulher se submete na procura pelos serviços. A noção de que há uma cultura já embutida em corpos, neste caso no corpo das mulheres, é correlata da ideia de Butler (2002, p. 163), de que "os corpos na 
verdade carregam discursos como parte de seu próprio sangue”. Nos regimes enunciativos, o corpo se constitui como a arena em que os embates políticos se dão, pois descortina o projeto biopolítico de medicalização do espaço social, ao mesmo tempo em que é substância, matéria e efeito de verdade. A questão do corpo e de suas possibilidades de entendimento/conhecimento é uma questão epistemológica (BUTLER, 2003), em que os corpos, tais quais os concebemos, são maneiras de conhecer como determinadas linguagens falam destes corpos, instituem-lhes existências, constituindo-os em seus processos de significação, conferindo-lhes a veracidade de suas "realidades".

A mulher está preocupada em apalpar o seu seio, em ir de seis em seis meses no ginecologista, fazer o preventivo. Alguma anomalia no seu corpo ela já sente, atrasou a menstruação ela já está preocupada. O homem, não. (participante de grupo focal, 35 anos).

Como a mulher se prepara a vida toda para ter filhos mantém uma vigia maior que o homem que não faz nada além de produzir espermatozóides, grosso modo. (Jovem de escola particular, 20 anos).

Acho que a principal diferença seria que a mulher tem um acompanhamento médico frequente, com sua ginecologista, além de se cuidarem mais com alimentação e não viverem tão preocupadas com seus trabalhos (...) talvez pela diferença de tratamento com mulheres, há a visão de a mulher ser mais frágil então deve se ter mais atenção, vejo também que há programas de saúde da mulher, quando não há nenhuma política pró-homens, tendo uma relação diferente com homens e mulheres. (Jovem de escola particular, 18 anos).

É pelo silenciamento que se pode apreender a relação dos homens com a saúde, pois a inteligibilidade dos homens neste campo é constituída justamente pela necessidade de investimento neste significante em favor de uma subversão produtiva do termo homens, sobre outras bases. Do silenciamento ecoam, neste sentido, as dificuldades relatadas pelos usuários, tanto no acesso aos serviços de saúde, como na falta de identificação destes com as instituições, radicalizada pela ausência de serviços específicos para esta população. Grande parte destas dificuldades se refere aos horários, visto que em horário comercial a maioria dos homens está no trabalho e reluta em reorganizar ou solicitar ao chefe a possibilidade de dispensa para tratamento ou prevenção.

Estou no meu serviço às 9 da manhã. Daí eu digo: eu estou mal, vou ao médico. Daí eu chego aqui e demoro seis horas para ser atendido. Eu vou chegar no meu serviço às seis horas da tarde? Eu vou chegar com o atestado de três da tarde? O que eu vou fazer? (participante de grupo focal, 22 anos). 
Quando pensados como "chefes de família", exclui-se dos processos de subjetivação destes homens a necessidade do cuidado com a saúde.

A mulher aceita a doença e faz o tratamento. O homem, por ser a cabeça da família, considera que é a cabeça da família e tem um processo depressivo maior. O homem assume menos. (Jovem de escola pública, 19 anos).

A gente chega lá, eles mandam a gente aguardar, aguardar, às vezes chega a tua vez e chega uma gestante, ou um velhinho, eu sei que eles têm a preferência, aí ele vai atender ela, aí vai atender o velhinho, e tu vai ficando, vai ficando, e aquilo vai me irritando. A gente sabe que eles precisam mais, mas a gente também precisa. Tu tens que resolver aquilo ali rápido porque tu tens uma família para sustentar (participante de grupo focal, 36 anos).

Alguns entrevistados apontam para a diferença entre as mulheres e os homens quanto a características como preocupação, paciência, delicadeza, entre outros, os quais influenciam direta e indiretamente na participação destes homens nos serviços de saúde, em comparação com as mulheres. Segundo os entrevistados, o homem procura ser mais valente, mais durão, tentando, em consequência, resolver seus problemas de saúde de forma prática e rápida, sem a necessidade de ir ao médico com frequência. Os homens têm mais resistência em ir ao médico, têm mais resistência em fazer controle periódico, e geralmente eles vão ou porque a mulher encaminhou, ou a mãe levou. Os homens têm muita dificuldade de demonstrar suas limitações, o que relacionam com aspectos históricos sobre masculinidade.

Muitos entrevistados atribuíram o maior cuidado das mulheres com sua saúde à estética, exigências sociais que às levam a maior preocupação com o corpo e, consequentemente, com a saúde. Ainda quanto a esta questão, a maior prevenção das mulheres é avaliada como consequência de uma maior preocupação com o corpo, a estética e saúde de maneira geral. Atribuem também esse pouco cuidado dos homens a fatores como preconceito e machismo, uma relação social e histórica representada nas seguintes falas:

Muitas vezes por causa do machismo. Homem pensa que não fica doente. Por isso procura pouco o médico para fazer exames preventivos. (Adulto nível fundamental, 45 anos).

Aqui surge a questão dos serviços de saúde serem, em sua maioria, voltados para atenção às mulheres, a ausência de serviços específicos de cuidados para homens, alimenta a ideia de um espaço ocupado e reservado às mulheres. Isso acaba por reforçar a relação historicamente mais significativa das mulheres com os serviços de assistência médica e uma não identificação dos homens com estes 
espaços. A saúde, substantivo feminino (FIGUEIREDO, 2005), não apenas

afasta os homens das esferas de cuidado, como também dita modelos normativos do que sejam práticas inteligíveis de cuidado.

A gente (homens) não se cuida um pouco é relaxamento, um pouco falta de tempo e o outro pouco é porque não tem para onde correr para ser atendido. Quem tem um plano de saúde tem uma oportunidade. Eu com 52 anos já devia ter feito no mínimo 3, 4 preventivo. Eu sei disso, assim como a mulher o homem também tem que fazer, ele é obrigado a fazer, só que não tem pra onde correr (participante de grupo focal, 52 anos).

Quando questionados sobre a existência de diferenças na forma como homens e mulheres enfrentam uma doença, os entrevistados relataram acreditar que os homens se sentem mais vulneráveis, por não estarem habituados a situações médicas, além de reclamarem mais, adiando enquanto é possível. São destaques, nesse sentido:

As mulheres são mais resistentes, tem menos medo de fazer exames, enfrentando as doenças e os tratamentos de maneira mais encorajadora. Os homens têm menos resistência, são moles, quando ficam doentes parece que o mundo vai acabar. (Adulto nível superior, 53 anos).

(...) homens relutam até não dar mais, então eles consultam um médico. Homens não levam a sério sua saúde, diferente da maioria das mulheres. (Adulto nível superior, 45 anos).

As mulheres são mais dramáticas. Tratam a doença de forma mais dolorosa. O homem é mais machão e não transparece. (Jovem de escola particular, 19 anos).

Os homens não são tão cuidadosos, raramente vão ao médico. São mais introvertidos em contar seus segredos. Alegam falta de tempo. As mulheres ao contrário do que afirmei são mais espontâneas, abertas. (Jovem de escola pública, 23 anos).

Nos enunciados sobre as mulheres e sua relação com o cuidado, o que permanece são as insígnias de inteligibilidade de um sujeito que, constituído no e pelo SUS, existe no ato de sua nomeação como um sujeito feminino, universal. É nestes regimes que os esforços coletivos para inserção dos homens no campo da saúde devem ser pensados, ou seja, neste campo discursivo em que alguns vetores de força são mantidos e, portanto, abertos à possibilidade de subversão dos próprios significados que os constituíram/constituem. É preciso lidar com as permanências dos significados que performatizam no imaginário social o ideal de mulher naturalmente cuidadora e maternal, para que outras formas de 
subjetivação possam ceder lugar a um cuidado que não esteja atrelado a este referencial histórico-cultural feminino.

Duas são as metáforas utilizadas por usuários participantes de grupos focais diferentes, para se referirem à relação que estabelecem com a instituição de saúde. A ideia de que o hospital é um fantasma na vida dos homens associa-se à de que a saúde pública é assustadora. Tem-se, desta forma, um par interessante para se analisar por onde estão sendo veiculadas as representaçôes de homens sobre os serviços de saúde, a partir de suas vivências. A fala é de um participante de 33 anos, do grupo focal realizado com os homens que se preparavam para a cirurgia da vasectomia, em resposta à pergunta "o que afasta os homens dos serviços de saúde?”.

\begin{abstract}
A saúde pública de um modo geral ela é assustadora, em todos os aspectos. Atendimento, conseguir uma vaga no posto, então já inibe o cara de procurar preventivamente, o homem. O homem já não vai, primeiro porque tem que levantar às 6 da manhã, 8 horas ele tem que estar no trabalho, se ele vai consultar ou não, só Deus sabe. Quando consegue ir para frente, no caso da vasectomia, é assustador, é complicado. (...) Você só vai ao médico quando é corretivo. Quando você pensa: - eu não consigo mais, eu estou morrendo (participante de grupo focal, 33 anos).
\end{abstract}

É possível perceber a partir desta pesquisa que a noção de saúde e o que ela engloba (prevenção, cuidado, doença) estão sendo questionados, exigindo novas leituras sobre este conceito na contemporaneidade. Isto significa dizer que "antes de excluir os homens das categorias de cuidado e saúde, faz-se necessário pensar nas significações que estas categorias adquiriram no universo masculino” (KNAUTH; MACHADO, 2005, p. 19). Implica também investigar como estão sendo significadas no universo feminino. Esta premissa inclui a clareza de como os serviços de saúde, de uma forma geral, acabam por refletir a organização social com base no gênero (NASCIMENTO, 2005), antes de afirmarmos que os homens se excluem ou foram excluídos das esferas de cuidado de si e dos outros.

\title{
Considerações Finais
}

Atualmente, já não parece novidade defender o argumento de que processos sociais relacionados ao gênero produzem diferenças nos comportamentos de proteção à saúde. Embora durante séculos quase todos os livros publicados fossem sobre homens (KIMMEL, 1997), existe uma enorme diferença entre se ter os homens como foco por se negligenciar a participação das mulheres na 
vida social e o fato recente de se ter os homens como objeto de estudo segundo o referencial de gênero (SCHRAIBER; GOMES; COUTO, 2005).

Há uma concordância ao se pensar a categoria relacional de gênero como fator de grande importância no padrão dos riscos de saúde nos homens e na forma como estes percebem e usam seus corpos. Tais tomadas de posição implicam, necessariamente, que "antes de excluir os homens das categorias de cuidado e saúde faz-se necessário pensar nas significaçōes que estas categorias adquiriram no universo masculino" (KNAUTH; MACHADO, 2005, p. 19). Isso implica também investigar como estão sendo significadas no universo feminino. Esta premissa inclui a clareza de como os serviços de saúde, de uma forma geral, acabam por refletir a organização social com base no gênero (NASCIMENTO, 2005), antes de afirmarmos que os homens se excluem ou foram excluídos das esferas de cuidado de si e dos outros.

Por meio das análises das falas apresentadas, é possível afirmar que o cuidado dos homens, no geral, está mais restrito aos cuidados com o corpo, por meio de uma vida menos sedentária, e que a procura por serviços médicos restringe-se a casos extremos, quando a doença já está instalada e os métodos caseiros de cura não foram suficientes para curá-la. Já as mulheres, por necessitarem realizar exames periódicos ginecológicos, acabam por procurar com mais frequência os serviços médicos, o que acaba por se tornarem mais "acostumadas" aos procedimentos dos serviços de saúde.

As dificuldades para a participação dos homens nos serviços de saúde estiveram presentes durante todas as entrevistas realizadas com os profissionais e usuários. Desde aspectos histórico-culturais às questões de infraestrutura da instituição estavam presentes nas respostas de muitos entrevistados. A dificuldade com o trabalho, em sair do emprego para vir ao posto de saúde ou ao hospital, foi levantada pelos profissionais e usuários como um dos principais impedimentos ao acesso dos homens aos serviços de saúde. A demora em ser atendido alia-se à falta no trabalho, que acaba não sendo justificada proporcionalmente ao tempo em que o usuário esperou pela consulta. As questôes relacionadas aos cuidados com a saúde e o significado de ser homem estão intimamente relacionadas. A instituição de saúde como um espaço de ação feminina, voltado às mulheres; a não-existência de programas e açōes voltadas aos homens, para atender a suas necessidades; a dificuldade de homens em procurar ajuda, em se verem contemplados nos serviços 
de saúde; as diferentes maneiras de cuidar de sua própria saúde, dos filhos, da família; o cuidado associado à dependência e à fraqueza, à manutenção de um ideal do que deva ser um homem; o desejo dos profissionais de falar e de transformar cenas cotidianas, permitindo que outros personagens atuem, são alguns dos ecos que podem ser registrados neste momento. Pistas, sem dúvida, deste/neste projeto sócio-político de refletir sobre os atuais desafios em Saúde Coletiva, a partir do que foi produzido nesta pesquisa em Florianópolis, Santa Catarina.

\section{Referências}

ARILHA, M. Homens, saúde reprodutiva e gênero: direitos em perspectiva. Projeto de doutorado. Faculdade de Saúde Pública da Universidade de São Paulo, São Paulo, 2001.

ARILHA, M. Políticas públicas de saúde e direitos reprodutivos no Brasil: um olhar para o futuro. In: ARILHA, M.; CITELI, M. T. (Org.). Políticas, mercado, ética: demandas e desafios no campo da saúde reprodutiva. São Paulo: Ed 34, 1998.

BUTLER, J. Fundamentos Contingentes: o feminismo e a questão do "pós-modernismo". In: Cadernos Pagu, v. 11, p. 11-42, 1998.

BUTLER, J. Problemas de gênero. Feminismo e subversão da identidade. Rio de Janeiro: Civilização Brasileira, 2003.

BUTLER, J. Como os corpos se tornam matéria: entrevista com Judith Butler. Revista estudos feministas, v. 10, n. 1, 2002.

BIRD, C.; RIEKER, P. Gender matters: an integrated model for understanding men's and women's health. Social Science \& Medicine, n. 48, p. 745-755, 1999.

CONNELL, R. W. Masculinities. Berkeley: University of California Press, 1995.

CONNELL, R.W. La organización social de la masculinidad. In: VALDÉS, T.; OLAVARRÍA, J. (Ed.). Masculinidadles. Santiago: Ediciones de las Mujeres, 1997.

COURTENAY, W.H. Engendering health. A social construcionist examination of men's health belief's and behaviors. Psychology of Men and Masculinity, v. 1, n. 1, p. 4-15, 2000.

COURTENAY, W.H. College men's health: an overview and a call to action. Journal of American College Health, v. 46, n. 6, 1998.

FIGUEIREDO, W. Assistência à Saúde dos Homens: um desafio para os serviços de atenção primária. Ciência e Saúde Coletiva. Rio de Janeiro, v. 10, n. 1, jan/mar 2005.

FRAGOSO, J.M.; KASHUBECK, S. Machismo, gender role conflict, and mental health in Mexican American men. Psychology of Men and Masculinity, v. 1, n. 2, p. 87-97, 2000.

FOUCAULT, M. O nascimento da clínica. Rio de Janeiro: Forense Universitária, 2003. 
FOUCAULT, M. O cuidado de si como prática de liberdade. In: MOTTA, M. (Org.). Michel

Foucault. Ditos e escritos: ética, sexualidade e política. v.5. Rio de Janeiro: Forense, 2004.

GIFFIN, K. A inserção dos homens nos estudos de gênero: contribuições de um sujeito histórico. Ciência \& Saúde Coletiva. Rio de Janeiro, v. 10, n. 1, jan/mar 2005.

GOMES, R.; NASCIMENTO, E.F.; ARAUJO, F.C. Por que os homens buscam menos os serviços de saúde do que as mulheres? As explicações de homens com baixa escolaridade e homens com ensino superior. Cadernos Saúde Pública [online], v. 23, n. 3, p. 565-574, 2007.

GOMES, R.; FERREIRA, E. A produção do conhecimento da saúde pública sobre a relação homem-saúde: uma revisão bibliográfica. Cadernos Saúde Pública, v. 22, n. 5, p. 901-911, 2006.

GREIG, A.; KIMMEL, M.; LANG, J. Men, masculinities \& development: broadening our work towards gender equality. Gender in Development Monograph, n. 10, UNPD: USA, 2000.

GUERRIERO, I.; AYRES, J.R.C.M.; HEARST, N. Masculinidade e vulnerabilidade ao HIV de homens heterossexuais. Saúde Pública, v. 36, n. 4, p. 50-60, 2002.

HEILBORN, M.L.; CARRARA, S. Em cena os homens. Revista Estudos Feministas, IFCS/ UFRJ, v. 6, n. 2, p. 370-374, 1998.

HERZLICH, C. Santé et maladie: analyse d'une représentation sociale. Paris: Muton, 1969.

KEIJZER, B. Hasta donde el cuerpo aguante: género, cuerpo y salud masculina. In: CACERES, C. et al. (Coord.). La salud como derecho ciudadano: perspectivas y propuestas desde América Latina. Lima: Facultad de Salud Pública y Administración de la Universidad Peruana Cayetano Herida, 2003. p. 137-152.

KEIJZER, B. Hasta donde el cuerpo aguante: género, cuerpo y salud masculina. La Manzana. Revista Internacional de Estúdios sobre masculinidades, v. 1, n. 1, enero/mayo 2006.

KIMMEL, M. Manhood in America. A cultural history. New York: Free Press, 1997.

KIMMEL, M.S. Homofobia, temor, vergüenza y silencio em la identidad masculina. In: VALDÉS, T.; OLAVARRÍA, J. (Org.). Masculinidades. Santiago: Isis Internacional, 1997. p. $49-62$.

KNAUTH, D.R.; MACHADO, P.S. Comentários ao artigo "Homens e saúde na pauta da Saúde Coletiva”. Ciênc. Saúde Coletiva [online], v. 10, n. 1, p. 18-19, 2005.

LYRA, J.; MEDRADO, B. Projeto de pesquisa Homens nos Serviços de Saúde: rompendo barreiras culturais, institucionais, individuais. Recife, São Paulo e Florianópolis, 2005.

MEDRADO, B. et al. Homens jovens no contexto do cuidado: leituras a partir da paternidade na adolescência. In ADORNO, R.C.F.; ALVARENGA, A.T.; VASCONCELOS, M.P.C. (Org.). Jovens, trajetórias, masculinidades e direitos. São Paulo: EdUSP, 2005.

MOSSE, G.L. The Image of Man: the creation of modern masculinity. New York: Oxford University Press, 1996. 
MÜLLER, R. F. Homens falados: performances de gênero e corpo nos paradoxos de serviços públicos de saúde. Dissertação (Mestrado em Psicologia) - Programa de Pós-graduação em Psicologia, Centro de Filosofia e Ciências Humanas Universidade Federal de Santa Catarina, Florianópolis, 2008. 132p.

NASCIMENTO, P. Homens e saúde: diversos sentidos em campo. Ciência e Saúde Coleti$v a$, v. 10, n. 1, jan./mar. 2005.

PLUMMER, D.C. The quest for modern manhood: masculine stereotypes, peer culture and the social significance of homophobia. Journal of Adolescence, v. 24, p. 15-23, 2001.

RIBEIRO, A.S.M.; ALMEIDA, A.M.O. Masculinidade: nova história, velhas representaçôes. In: CAMPOS, P.H.F.; LOUREIRO, M.C.S. (Org.). Representaçôes sociais e práticas educativas. Goiânia: EdUCG, 2003. P. 145-167.

ROBERTSON, J.M.; FITZGERALD, L.F. Overcoming the masculine mystique. Preferences for alternative forms of assistence among men who avoid counseling. Journal of Counseling Psychology, v. 39, n. 2, p. 240-246, 1992.

SABO, D. Compreender la salud de los hombres. OPS: Harvard Center for Population and Development Studies, 2000.

SCHRAIBER, L.B.; GOMES, R.; COUTO, M.T. Homens e saúde na pauta da Saúde Coletiva. Ciência \& Saúde Coletiva, v. 10, n. 1, p.7-17, jan/mar 2005.

SCOTT, J. Gênero: uma categoria útil de análise histórica. Revista Educação e Realidade, Porto Alegre, v. 20, n. 2, p. 71-99, jul./dez 1995.

SCOTT, J. O enigma da igualdade. Revista Estudos Feministas. Florianópolis, v. 13, n. 1, 2005.

SIQUEIRA, M.J.T. A constituição da identidade masculina: alguns pontos para discussão. Psicol. USP [online], v. 8, n. 1, p. 113-130, 1997.

SIQUEIRA, M.J.T. Saúde e direitos reprodutivos: o que os homens têm a ver com isso? Dossiê "Relações de Gênero e Saúde Reprodutiva”. Revista Estudos Feministas, v. 8, n. 1, 2000. WADE, J.C.; BRITTAN-POWELL, C. Men's attitudes toward race and gender equity: the importance of masculinity ideology, gender-related traits, and reference group identity dependence. Psychology of Men and Masculinity, v. 2, n. 1, p. 42-50, 2001.

\section{Notas}

${ }^{1}$ Para ler o discurso na íntegra, ver site do Ministério da Saúde: saúde: www.saude.gov.br.

${ }^{2}$ Destacam-se, neste sentido, a política de humanização do parto e nascimento, o Programa MãeCanguru, os grupos de casais grávidos, as instalações da Unidade de Alojamento Conjunto da Maternidade (em consonância com a Lei do Acompanhante $\mathrm{n}^{\circ}$. 11108), além de medidas educativas voltadas ao planejamento familiar e à prevenção das DSTs/Aids.

${ }^{3}$ Roteiro conforme projeto de pesquisa multicêntrico "Homens e serviços de Saúde: rompendo barreiras institucionais, individuais e culturais", realizada anteriormente pelo Núcleo Margens da UFSC, 
${ }^{4}$ Universidades participantes: Universidade Federal de Santa Catarina, Universidade Federal do Espírito Santo, Universidade de Brasília e o Instituto Papai de Recife/PE. Órgão Financiador: CNPq.

${ }^{5}$ Muitos entrevistados relataram práticas de cuidado com a saúde que diferem das idas frequentes ao médico, como por exemplo, este entrevistado de 50 anos, ao afirmar que "eu não tenho colesterol, eu não tenho nada, não tomo um comprimido, eu me cuido também. Uma das coisas que eu faço diariamente, que eu tomo diariamente, de manhã cedo, eu pego duas folhas de couve mineira, bato ela no liquidificador com meio copo de leite e uma colher de aveia”. Este é um importante aspecto a ser considerado na conceituação do que sejam cuidados com a saúde, para escapar e principalmente poder reconhecer o que os entrevistados consideram como cuidados com a saúde, além da rotina preventiva. Sem dúvida, um modo de se aproximar também do conceito de saúde integral do SUS, no movimento de cuidado com o próprio corpo que não passa, necessariamente, pelo submetimento deste corpo ao saber médico.

${ }^{6}$ Todos os nomes são fictícios. 


\section{Abstract}

\section{Masculinities and health practices: portraits of a research experience in Florianopolis (SC), Brazil}

This paper aims to present partial results of the multicentered research "Masculinities and Health Practices". This research explored the meanings of health and illness among the male population in Florianopolis and the healthcare adopted by them. The research methodology was based on seven focal groups with male patients of the local health services, interviews with the professionals who take part of the sexual health and reproductive team of the Santa Catarina University Hospital, as well as 260 interviews with males. It also explored gender discursive practices of the medical team (doctors, nurses, psychologists, social assistants, and health professionals in general) regarding healthcare and the availability of the services for the male population. Judith Butler's philosophical and methodological proposals regarding intelligible gender, performances and its consequences for the constitution of the subjects was the theoretical vector of analyses of the empirical material. The paper also considers the biopolitical project that encapsulated these ideas, in particular the Unified Health System (SUS) and its principles of universality, integral care and equity. The concept of gender is a key element of the health risk pattern among the males and how they perceive, act and take care of their bodies, both as possibility of values transformations or reiteration of current values.

> Key words: males, health, masculinities. 